\title{
Erratum: Source size measurement options for low-emittance light sources [Phys. Rev. Accel. Beams 23, 024801 (2020)]
}

\author{
N. Samadiø, X. Shi, L. Dallin, and D. Chapman \\ (Q) (Received 17 September 2021; published 10 November 2021)
}

DOI: 10.1103/PhysRevAccelBeams.24.119901

Errors were found in Eq. (16) and its introductory phrase, which should read as follows:

The magnitude of the relative size error $d \sigma_{y} / \sigma_{y}$ can be obtained from Eq. (15) as

$$
\frac{d \sigma_{y}}{\sigma_{y}}=\frac{|d V|}{2 V \ln \frac{1}{V}}
$$

These errors do not affect any of the results and conclusion of the paper.

Published by the American Physical Society under the terms of the Creative Commons Attribution 4.0 International license. Further distribution of this work must maintain attribution to the author(s) and the published articles title, journal citation, and DOI. 